\title{
Papers
}

\section{Incidence and remission rates of lower urinary tract symptoms at one year in women aged 40-60: longitudinal study}

Lars Alling Møller, Gunnar Lose, Torben Jørgensen

\begin{abstract}
Objectives To determine the incidence and rates of remission of lower urinary tract symptoms at one year in women aged 40-60, and to assess factors associated with remission.

Design Ongoing longitudinal cohort study. Setting One rural and one urban county in Denmark. Participants 4000 women recruited on a random basis, 2860 of whom were followed up at one year. Measurements Incidence and rates of remission of lower urinary tract symptoms.

Results Prevalence, incidence, and rates of remission of lower urinary tract symptoms in 2284 women were respectively $28.5 \%$ (95\% confidence interval $26.7 \%$ to $30.4 \%), 10.0 \%$ (8.5\% to $11.4 \%)$, and $27.8 \%(25.6 \%$ to $30.0 \%)$. Overall, symptoms were not significantly associated with events performed or initiated in the study period: medical consultation (1.6, 0.8 to 2.8 ), pelvic floor physiotherapy $(0.9,0.5$ to 1.8$)$, treatment with antibiotics on suspicion of a lower urinary tract infection (1.3, 0.8 to 2.2$)$, or other treatment $(1.7,0.7$ to 4.1). Many of the individual symptoms were, however, associated with seeking professional help. Conclusions Lower urinary tract symptoms constitute dynamic conditions, with women experiencing more or fewer symptoms, and eventually a cessation of symptoms. The distinction between permanent and fluctuating cases may have important clinical and scientific implications.
\end{abstract}

\section{Introduction}

Urinary incontinence and other lower urinary tract symptoms are common among women of all ages. ${ }^{1-7}$ The impact of the clinical course of lower urinary tract symptoms has only been considered infrequently, ${ }^{8-12}$ yet the extent to which symptoms arise and established symptoms decrease or cease influences outcome assessment. Studies have shown that despite an increased prevalence of urinary incontinence with age most individuals do improve. ${ }^{8911}$ To determine the proportion of women in whom symptoms change and eventually cease and to identify associated factors may help to target treatment resources and preventive steps.

Various factors associated with lifestyle are thought to precipitate lower urinary tract symptoms and urinary incontinence-for example, weight, physical forces (exercise, work), smoking, caffeine and fluid intake, constipation, posture.$^{13-18}$ No randomised studies on intervention have been published. It seems feasible, however, that adjustment or adaptation to one or more factors may influence the frequency of symptoms over time.

The estimated annual incidence of urinary incontinence in women aged $42-74$ is $2.0-2.5 \%,{ }^{10}{ }^{12}$ and the estimated annual rate of remission of urinary incontinence in women aged 60 or more is 3.3-12.0\%.$^{8911}$ Longitudinal data on these common symptoms are, however, sparse.

We aimed to assess the dynamic clinical course of lower urinary tract symptoms by determining both the incidence and rates of remission of such symptoms at one year and the factors attributable to remission in women aged 40-60.

\section{Participants and methods}

Between 15 and 20 June 1996 we sent a questionnaire to 4000 women selected at random from the Danish civil registration system, a system whereby Danish people are identified for life by a unique 10 digit number. Personal details of the women are published elsewhere. ${ }^{7}$

One year later 2860 women received a follow up questionnaire. Non-responders were sent a reminder after three weeks and if they still failed to respond were eventually asked to complete a short form comprising questions on urgency and incontinence. This procedure followed guidelines outlined by the local ethical committee. The baseline questionnaire included data on age, urinary incontinence, daytime frequency, nocturia, postmicturition dribble, straining, urgency, incomplete bladder emptying, and hesitancy. Women were asked about leakage caused by coughing or sneezing, moving, lifting, sleeping, sexual intercourse, urgency, and rest. We defined stress incontinence according to the International Continence Society as leakage caused by exertion (coughing or sneezing, moving, or lifting) and urge incontinence as leakage associated with urgency. ${ }^{19}$

We have suggested that an appropriate cut off point for lower urinary tract symptoms in an epidemiological context is symptoms occurring weekly or more. ${ }^{7}$ Incidence was therefore defined as the proportion of women in whom symptoms arise or increase from

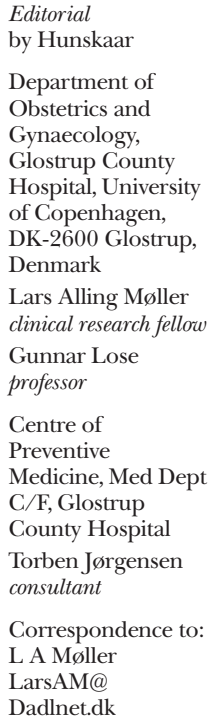

BMJ 2000;320:1429-32 
Table 1 Baseline data of 2284 women included in study and 576 who dropped out, at one year follow up. Values are numbers (percentages) unless stated otherwise

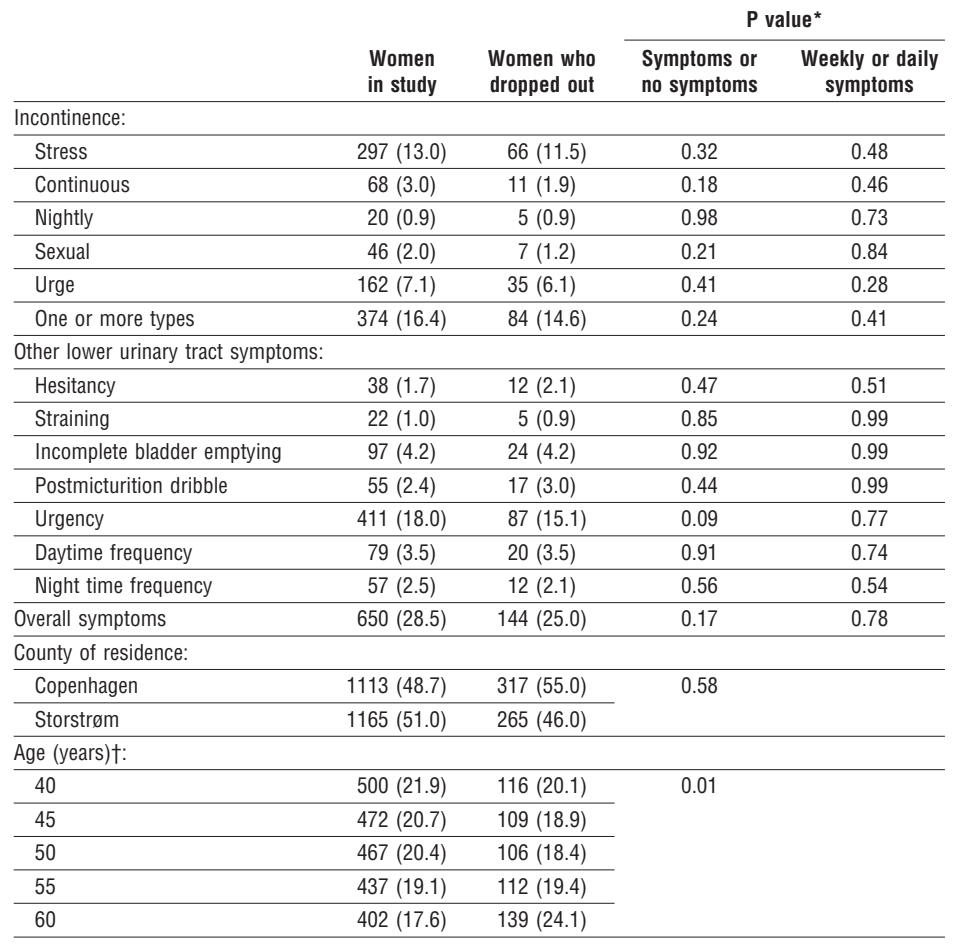

${ }^{*} \chi^{2}$ test, $\mathrm{df}=1 . \mathrm{ddf}=4$
Validity and reproducibility of the final questionnaire tested fair. ${ }^{7}$ The kappa statistics of the main outcome measures ranged from 0.58 to 0.92 .

The follow up questionnaire at one year was similar to the baseline questionnaire. During the study period activities performed or initiated with the intention to treat lower urinary tract symptoms were recorded: consulting a doctor, drugs prescribed, and pelvic floor physiotherapy. Our study was approved by the local ethical committee.

\section{Statistical methods}

We applied the $\chi^{2}$ test, McNemar's test, the MannWhitney test with correction for ties, and multivariate logistic regression analysis with Statview when appropriate. We considered a 5\% level as significant.

\section{Results}

Overall, we included 2860 of $4000(71.5 \%)$ women at baseline. Non-responders did not differ from participants in age and county of residence but had significantly fewer complaints about incontinence and urgency. ${ }^{7}$ After one year 2284 (79.9\%) women completed the follow up questionnaire and were included in the follow up study. Women who dropped out tended to be older than included women. However, we found no significant difference in the occurrence or severity of baseline symptoms (weekly or daily) between included women and those who dropped out (table 1).

The prevalence, incidence, and rate or remission of lower urinary tract symptoms were 28.5\% (95\% confidence interval $26.7 \%$ to $30.4 \%), 10.0 \%$ (8.5\% to $11.4 \%$ ), and $27.8 \%$ (25.6\% to $30.0 \%$ ) respectively (table 2). The difference in frequency of symptoms at baseline and at one year follow up were insignificant (table 2). The incidence of and rates of remission of the subtypes of lower urinary tract symptoms ranged from $0.6 \%$ to $6.1 \%$ (median $4.5 \%$ ) and $29.0 \%$ to $59.7 \%$ (median $39.5 \%$ ) respectively (table 2 ).

Table 2 Follow up data at one year for 2277 women. Values are percentages $(95 \% \mathrm{Cls})$ unless stated otherwise

\begin{tabular}{|c|c|c|c|c|c|c|}
\hline & \multirow[b]{2}{*}{ No } & \multicolumn{3}{|c|}{ Cross sectional data } & \multicolumn{2}{|c|}{ Longitudinal data } \\
\hline & & $\begin{array}{c}\text { Prevalence at } \\
\text { baseline }\end{array}$ & $\begin{array}{c}\% \text { at one year } \\
\text { follow up }\end{array}$ & P value * & Incidence & Remission rate \\
\hline \multicolumn{7}{|l|}{ Incontinence: } \\
\hline Laughing or coughing & 2200 & $12.1(10.7$ to 13.4$)$ & 10.4 & 0.102 & $3.6(2.8$ to 4.4$)$ & $38.9(36.7$ to 41.0$)$ \\
\hline Moving & 2190 & 5.7 (4.7 to 6.6$)$ & 3.7 & 0.003 & 1.5 (1.0 to 2.1$)$ & 59.7 (57.6 to 61.8$)$ \\
\hline Heavy lifting & 2245 & $3.3(2.6$ to 4.1$)$ & 3.0 & 0.630 & $1.2(0.8$ to 1.7$)$ & 45.3 (43.2 to 47.4$)$ \\
\hline Stresst: & 2275 & 13.1 (11.7 to 14.4$)$ & 11.0 & 0.046 & $4.0(3.2$ to 4.9$)$ & 41.4 (39.2 to 43.6$)$ \\
\hline At rest & 2218 & 3.1 (2.3 to 3.8$)$ & 2.4 & 0.188 & $1.0(0.6$ to 1.4$)$ & $50.0(47.9$ to 52.1$)$ \\
\hline Nightly & 2226 & 3.1 (2.3 to 3.8$)$ & 2.4 & 0.188 & $0.4(0.1$ to 0.7$)$ & $55.0(52.9$ to 57.1$)$ \\
\hline Sexual & 2240 & 2.1 (1.5 to 2.6) & 1.7 & 0.388 & $0.7(0.4$ to 1.1$)$ & 47.8 (45.7 to 49.9$)$ \\
\hline Urge & 2205 & 7.3 (6.3 to 8.4$)$ & 6.7 & 0.486 & 2.7 (2.0 to 3.4$)$ & 42.0 (39.8 to 44.1$)$ \\
\hline One or more types & 2277 & $16.4(14.9$ to 17.9$)$ & 14.8 & 0.184 & 5.8 (4.7 to 6.8$)$ & 37.7 (35.5 to 39.9$)$ \\
\hline \multicolumn{7}{|c|}{ Other lower urinary tract symptoms: } \\
\hline Hesitancy & 2235 & 1.7 (1.2 to 2.2$)$ & 2.3 & 0.189 & $1.4(0.9$ to 1.9$)$ & 39.5 (37.4 to 41.5$)$ \\
\hline Straining & 2223 & $1.0(0.6$ to 1.4$)$ & 1.0 & 0.881 & $0.6(0.3$ to 1.0$)$ & $59.1(57.0$ to 61.1$)$ \\
\hline Incomplete bladder emptying & 2266 & $4.3(3.4$ to 5.1$)$ & 4.5 & 0.802 & 2.6 (2.0 to 3.3$)$ & 51.5 (49.4 to 53.6$)$ \\
\hline Postmicturition dribble & 2251 & $2.4(1.8$ to 3.1$)$ & 2.8 & 0.459 & $1.5(1.0$ to 2.0$)$ & $40.0(38.0$ to 42.0$)$ \\
\hline Urgency & 2268 & 18.1 (16.5 to 19.7) & 17.3 & 0.545 & $6.1(5.0$ to 7.2$)$ & $29.0(26.9$ to 31.0$)$ \\
\hline Daytime frequency & 2235 & $3.5(2.8$ to 4.3$)$ & 3.8 & 0.655 & $1.7(1.1$ to 2.2$)$ & 36.7 (34.7 to 38.7$)$ \\
\hline Night time frequency & 2196 & 2.6 (1.9 to 3.3$)$ & 3.1 & 0.372 & $1.6(1.1$ to 2.2$)$ & 36.8 (34.8 to 38.9$)$ \\
\hline Overall symptoms & 2277 & 28.5 (26.7 to 30.4$)$ & 27.5 & 0.542 & $10.0(8.5$ to 11.4$)$ & $27.8(25.6$ to 30.0$)$ \\
\hline
\end{tabular}

*McNemar's test.

†One or more of laughing or coughing, moving, or lifting heavy objects. 
Table 3 shows the changes in incontinence symptoms reported at one year follow up compared with baseline data; one woman $(0.8 \%)$ with daily incontinence at baseline reported no symptoms and 26 women $(20.6 \%)$ reported symptoms only sometimes at one year, and 11 women $(4.5 \%)$ with weekly incontinence at baseline reported no symptoms and $116(46.9 \%)$ reported fewer than weekly symptoms at one year. Most, but not all, types of lower urinary tract symptoms improved during the study period as a consequence of medical awareness, performance of pelvic floor physiotherapy, or drugs (table 4).

\section{Discussion}

This is the first longitudinal study to assess the clinical course of lower urinary tract symptoms in middle aged women. We studied 4000 women aged 40-60 years randomly selected from the general population. The estimated incidence and rates of remission of symptoms were $10.0 \%$ and $59.7 \%$ respectively.

Evidence is continuously growing on the prevalence of urinary incontinence and lower urinary tract symptoms in women of all ages, ${ }^{1-7}$ yet few studies have dealt with outcome in the long term. ${ }^{8-12}$

In longitudinal studies based on a questionnaire design it is essential to know if differences between answers are real or due to inadequate instrumentation. We therefore calibrated, validated, and tested the questionnaire even though it had been validated previously. ${ }^{20}{ }^{21}$ The reproducibility of the revised questionnaire was fair to excellent. ${ }^{7}$ Reproducibility had not been evaluated in previous longitudinal studies. ${ }^{8-22}$

Our estimated annual incidence of urinary incontinence of $5.8 \%$ corresponded well with the 2.0-2.5\% reported in other studies. ${ }^{10}{ }^{12}$ Rates of remission in women aged 60 or more range from 3.3\% to $12.0 \% .^{811}$ Our study found a rate of remission in women aged 40-60 of about 30\%. These large differences are probably related to differences in study design and definitions.

No intervention was scheduled as we wanted to study the normal clinical course of lower urinary tract symptoms. It is likely, however, that by simply receiving
Table 3 Urinary incontinence in women at one year follow up compared with baseline data. Values are percentages

\begin{tabular}{lcccc} 
& \multicolumn{4}{c}{ One year follow up } \\
\cline { 2 - 5 } Prevalence & Never & Sometimes & Weekly or more & Daily or more \\
\hline Never & 69.0 & 28.9 & 1.4 & 0.7 \\
\hline Sometimes & 11.8 & 79.8 & 7.6 & 0.8 \\
\hline Weekly or more & 4.5 & 46.9 & 39.9 & 8.6 \\
\hline Daily or more & 0.8 & 20.6 & 31.0 & 47.6 \\
\hline
\end{tabular}

and answering questionnaires the women may have become aware of our aim. As part of the validation of our questionnaire we interviewed a subgroup of women with lower urinary tract symptoms, focusing on specific items. Some of these women asked for and received simple advice. To determine the magnitude of the influence of this advice on symptoms, we assessed the effects of consulting a doctor, drugs, and pelvic floor physiotherapy.

Although effective on individual symptoms no single treatment modality had a beneficial effect on lower urinary tract symptoms overall. This may be because the definition of lower urinary tract symptoms is commonly used to describe several symptoms with a variety of causes. As many items on the questionnaire were interrelated it was not possible from this analysis to assess the importance of each individual item. Our analysis does, however, indicate that some bias may have been introduced.

The effect of several factors on rates of remission have been studied: age, parity, body mass index, change in body mass index, functional limitations as measured by the Rosow-Breslau scale and by impairment in activities of daily living, stroke, Parkinson's disease, myocardial infarction, constipation, oestrogen use, and drugs. ${ }^{11}$ The only factors significantly associated with an increased incidence and rate of remission were age and improvement in activities of daily living respectively. ${ }^{11}$ These factors were only examined at baseline interview. In perimenopausal women a change in hormonal status may be an important cause of fluctuating lower urinary tract symptoms, but this was not studied.

In conclusion, we found that during the clinical course of lower urinary tract symptoms women experi-

Table 4 Remission of lower urinary tract symptoms at one year follow up stratified to possible associated factors (each factor adjusted for age). Values are odds ratios (95\% Cls) unless stated otherwise

\begin{tabular}{|c|c|c|c|c|c|c|c|c|}
\hline & Attended doctor & $\begin{array}{c}P \\
\text { value }\end{array}$ & $\begin{array}{l}\text { Pelvic floor } \\
\text { physiotherapy }\end{array}$ & $\begin{array}{c}P \\
\text { value }\end{array}$ & Antibiotics* & $\begin{array}{c}P \\
\text { value }\end{array}$ & Treatment† & $\begin{array}{c}P \\
\text { value }\end{array}$ \\
\hline \multicolumn{9}{|l|}{ Incontinence: } \\
\hline Stress & $2.4(1.3$ to 4.3$)$ & 0.005 & $2.0(1.1$ to 3.6$)$ & 0.462 & $1.0(0.5$ to 2.0$)$ & 0.952 & $2.1(0.8$ to 5.5$)$ & 0.154 \\
\hline Urge & $2.8(1.3$ to 5.7$)$ & 0.009 & $2.8(1.4$ to 5.7$)$ & 0.006 & $2.1(1.1$ to 4.1$)$ & 0.044 & $2.2(0.7$ to 7.3$)$ & 0.243 \\
\hline Continuous & $4.7(2.0$ to 11.0$)$ & 0.001 & 6.7 (2.7 to 13.2$)$ & $<0.0001$ & 2.8 (1.2 to 6.5$)$ & 0.015 & $4.8(1.4$ to 16.3$)$ & 0.038 \\
\hline Nightly & $6.6(1.7$ to 25.2$)$ & 0.016 & $6.1(1.6$ to 23.1$)$ & 0.040 & $3.9(1.0$ to 14.9$)$ & 0.050 & $10.9(2.3$ to 52.0$)$ & 0.015 \\
\hline Sexual & $5.4(2.0$ to 14.9$)$ & 0.001 & $1.6(0.4$ to 6.7$)$ & 0.459 & $2.4(0.8$ to 7.1$)$ & 0.110 & 7.9 (2.3 to 27.8$)$ & 0.001 \\
\hline \multicolumn{9}{|c|}{ Other lower urinary tract symptoms: } \\
\hline Hesitancy & $2.7(0.6$ to 12.0$)$ & 0.217 & - & 0.986 & $1.6(0.4$ to 7.1$)$ & 0.584 & $3.3(0.4$ to 25.4$)$ & 0.311 \\
\hline Straining & $5.3(1.4$ to 19.3$)$ & 0.012 & $1.5(0.19$ to 11.6$)$ & 0.713 & 0.9 (0.11 to 6.7$)$ & 0.880 & $3.9(0.5$ to 30.5$)$ & 0.193 \\
\hline Incomplete bladder emptying & $2.9(1.2$ to 6.7$)$ & 0.012 & $1.4(0.5$ to 4.0$)$ & 0.560 & $1.8(0.8$ to 4.0$)$ & 0.154 & $4.4(1.5$ to 12.7$)$ & 0.008 \\
\hline Postmicturition dribble & $4.0(1.3$ to 11.9$)$ & 0.018 & 5.0 (1.8 to 13.9$)$ & 0.004 & 4.2 (1.6 to 11.0$)$ & 0.004 & 8.0 (2.3 to 28.3$)$ & 0.002 \\
\hline Urgency & $2.3(1.2$ to 4.2$)$ & 0.009 & $1.5(0.8$ to 3.0$)$ & 0.25 & $1.9(1.1$ to 3.2$)$ & 0.028 & $1.7(0.6$ to 4.8$)$ & 0.37 \\
\hline Daytime frequency & $3.7(1.4$ to 9.8$)$ & 0.011 & $1.8(0.6$ to 6.2$)$ & 0.397 & $1.2(0.4$ to 4.0$)$ & 0.786 & $1.7(0.2$ to 12.5$)$ & 0.699 \\
\hline Night time frequency & $3.0(0.9$ to 10.1$)$ & 0.132 & 2.7 (0.8 to 9.2$)$ & 0.217 & $2.4(0.8$ to 7.3$)$ & 0.148 & 4.9 (1.1 to 21.9$)$ & 0.070 \\
\hline Overall & $1.6(0.8$ to 2.8$)$ & 0.147 & $0.9(0.5$ to 1.8$)$ & 0.747 & $1.3(0.8$ to 2.2$)$ & 0.343 & $1.7(0.7$ to 4.1$)$ & 0.268 \\
\hline
\end{tabular}

${ }^{\star}$ Infection suspected.

†Non-infectious cause suspected. 


\section{What is already known on this topic}

In perimenopausal women the prevalence of urinary incontinence is about $10-15 \%$

Several factors are responsible for lower urinary tract symptoms

Little is known about the prevalence and clinical course of lower urinary tract symptoms, and knowledge about the clinical course is an important consideration in treatment

\section{What this study adds}

During the clinical course of lower urinary tract symptoms women experience more or fewer symptoms

An awareness of why these changes occur can help in decisions about treatment
3 Milsom I, Ekelund P, Molander U, Arvidsson L, Areskoug B. The influence of age, parity, oral contraception, hysterectomy and menopause on the prevalence of urinary incontinence in women. J Urol 1993;149: 1459-62.

4 Yarnell JW, Voyle GJ. The prevalence and severity of urinary incontinence in women. J Epidemiol Community Health 1981;35:71-4.

5 Samuelsson E, Victor A, Tibblin G. A population study of urinary incontinence and nocturia among women aged 20-59 years. Prevalence, well-being and wish for treatment. Acta Obstet Gynecol Scand 1997;76: 74-80.

6 Sommer P, Bauer T, Nielsen KK, Kristensen ES, Hermann GG, Steven K, et al. Voiding patterns and prevalence of incontinence in women. A questionnaire survey. Br J Urol 1990;66:12-5.

7 Møller LA, Lose G, Jørgensen T. The prevalence and bothersomeness of lower urinary tract symptoms in women 40-60 years of age. Acta Obstet Gynecol Scand 2000;79:298-305.

8 Campbell AJ, Reinken J, McCosh L. Incontinence in the elderly: prevalence and prognosis. Age Ageing 1985;14:65-70.

9 Herzog AR, Diokno AC, Brown MB, Normolle DP, Brock BM. Two-year incidence, remission, and change patterns of urinary incontinence in noninstitutionalized older adults. J Gerontol 1990;45:M67-74.

10 Burgio KL, Matthews KA, Engel BT. Prevalence, incidence and correlates of urinary incontinence in healthy, middle-aged women. I Urol 1991:146:1255-9.

11 Nygaard IE, Lemke JH. Urinary incontinence in rural older women: prevalence, incidence and remission. J Am Geriatr Soc 1996;44:1049-54.

12 Holtedahl K, Verelst M, Schiefloe A. A population based, randomized, controlled trial of conservative treatment for urinary incontinence in women. Acta Obstet Gynecol Scand 1998;77:671-7.

ence more or fewer symptoms. Specific reasons for remission and rates of remission in women seeking treatment remain to be elucidated.

This study was supported with grants from Coloplast; Pharmacia and Upjohn; the research foundation of Bornholm, Frederiksborg, Roskilde, Storstrøms, and Vestsjællands counties; the Rudolph Foundation; the Kleins Foundation; the research foundation of Copenhagen, Faroe Island, and Greenland; the foundation of Niels and Desirees Yde; and the county hospital of Nykøbing Falster.

Contributors: LAM performed the study, corresponded with the patients, analysed the data, and wrote the paper. GL had the original idea for the study and helped with the study design, data analysis, and writing the paper. TJ helped with the study design, data analysis, and writing the paper. All authors will act as guarantors for the paper.

Conflict of interest: None declared.

1 Thomas TM, Plymat KR, Blannin J, Meade TW. Prevalence of urinary incontinence. BMJ 1980;281:1243-5.

2 Elving LB, Foldspang A, Lam GW, Mommsen S. Descriptive epidemiology of urinary incontinence in 3,100 women age 30-59. Scand J Urol Nephrol Suppl 1989;125:37-43.
13 Nygaard IE, Thompson FL, Svengalis SL, Albright JP. Urinary incontinence in elite nulliparous athletes. Obstet Gynecol 1994;84:183-7.

14 Bump RC, McClish DK. Cigarette smoking and urinary incontinence in women. Am J Obstet Gynecol 1992;167:1213-8.

15 Jozwik M. Stress urinary incontinence in women-an overuse syndrome Med Hypotheses 1993;40:381-2.

16 Mommsen S, Foldspang A. Body mass index and adult female urinary incontinence. World J Urol 1994;12:319-22.

17 Diokno AC, Brock BM, Herzog AR, Bromberg J. Medical correlates of urinary incontinence in the elderly. Urology 1990;36:129-38.

18 Creighton SM, Stanton SL. Caffeine: does it affect your bladder? Br J Urol 1990;66:613-4. terminology of lower urinary tract function. $\mathrm{Br} J$ Obstet Gynaecol 1990;97:1-16.

20 Bernstein I, Sejr T, Able I, Andersen JT, Fischer-Rasmussen W, Klarskov P, et al. Assessment of lower urinary tract symptoms in women by a self-administered questionnaire: test-retest reliability. Int Urogynecol J Pelvic Floor Dysfunct 1996;7:37-47.

21 Jackson S, Donovan J, Brookes S, Eckford S, Swithinbank L, Abrams P. The Bristol female lower urinary tract symptoms questionnaire: development and psychometric testing. Br J Urol 1996;77:805-12

22 Holtedahl K, Hunskaar S. Prevalence, 1-year incidence and factors associated with urinary incontinence: a population based study of women 50-74 years of age in primary care. Maturitas 1998;28:205-11

(Accepted 2 February 2000)
19 Abrams P, Blaivas JG, Stanton SL, Andersen JT. The standardisation and

\section{Association between psychosocial work characteristics and health functioning in American women: prospective study}

Yawen Cheng, Ichiro Kawachi, Eugenie H Coakley, Joel Schwartz, Graham Colditz

Department of

Health and Social

Behavior, Harvard

School of Public

Health, Boston,

MA 02115, USA

Yawen Cheng

research fellow

Harvard Center for Society and Health, Harvard School of Public Health

Ichiro Kawachi

director

continued over

BMJ 2000;320:1432-6

\begin{abstract}
Objective To examine prospectively the relation between psychosocial work characteristics and changes in health related quality of life over four years in a cohort of working women in the United States.

Design Longitudinal cohort study.

Setting United States.
\end{abstract}

Participants 21290 female registered nurses who completed the Karasek's job content questionnaire and a modified version of the short form 36 questionnaire (SF-36) as used for a survey of health status by the medical outcomes study.

Main outcome measures Seven dimensions of health status: physical functioning, role limitations due to physical health problems, bodily pain, vitality, social functioning, role limitations due to emotional problems, and mental health.

Results Examined separately low job control, high job demands, and low work related social support were associated with poor health status at baseline as well as greater functional declines over the four year follow up period. Examined in combination, women with low job control, high job demands, and low work related social support ("iso-strain" jobs) had the greatest functional declines. These associations could not be explained by age, body mass index, comorbid disease status, alcohol consumption, smoking status, education level, exercise level, employment status, marital status, or presence of a confidant.

Conclusions Adverse psychosocial work conditions are important predictors of poor functional status and its decline over time. 